\title{
När vården flyttar hem till dig - den mobila vårdens etik
}

\author{
Elin Palm
}

Västvärldens åldrande befolkning anses ofta ställa krav på nya former av vård och omsorg. Olika typer av informations- och kommunikationstekniskt (IKT) baserat vårdstöd framhålls ofta som en lösning. Tekniken medger en rad olika fördelar, exempelvis tätare tillsyn, kontinuerliga mätningar av vitala funktioner, med möjlighet att kontinuerligt ställa diagnos, och snabb respons på larm, men de tekniska lösningarna får också etiska implikationer. I den här artikeln beskrivs och exemplifieras IKT-baserad vård och omsorg och teknikens påverkan på centrala värden som personlig integritet, autonomi, frivillighet och informerat samtycke diskuteras. Interaktiv etisk teknikvärdering föreslås för att bättre inkorporera alla berörda parters behov av och synpunkter på den här typen av vårdstöd.

Nyckelord: autonomi, etik, frivillighet, informerat samtycke, interaktiv etisk teknikvärdering, IKT-baserat vårdstöd, hemvård, personlig integritet, robotteknik, sensorteknik, säkerhet, trygghet, valfrihet

\section{English summary: When health care moves in - the ethics of mobile health care}

An ageing population in the Western world is typically taken to require novel forms of health care. Different types of Information and Communication (ICT) based services and functions are presented as a solution. Even if such technology imply benefits in terms of more frequent attendance, continuous monitoring and diagnoses of vital signs and quick response to alarms, the technology also gives raise to ethical concerns. This article describes and exemplifies ICT-based health care and discusses implications on central values like privacy, autonomy, freedom of choice and informed consent. Interactive ethi- 
cal technology assessment is suggested as a means to better incorporate the needs of all concerned parties and their perspectives on this type of support.

Key words: autonomy, ethics, freedom of choice, informed consent, interactive ethical technology assessment, ICT-based health care, home-care, privacy, robot technology, sensor technology, security

\section{Inledning}

Den utvecklade världens befolkning åldras och den vårdsituation som detta ger upphov till liknas ibland vid en tidsinställd bomb (Martin, Williams \& O’Neill 2009). I länder som Spanien, Italien, Japan och USA går det snart två personer i gruppen 65 år och äldre på varje person i gruppen 20 år och yngre, och den högsta levnadsåldern förskjuts ständigt uppåa. ${ }^{1}$ Eftersom en större andel av personerna i segmentet 65 år och äldre lider av kroniska sjukdomar antas det att den åldrande befolkningen kommer att omkullkasta rådande vård-, sjukförsäkrings- och pensionssystem. Det antas att den demografiska utvecklingen och en växande ohälsa bland yngre kommer att kräva att det rådande vård- och omsorgssystemet förändras, ${ }^{2}$ och ofta framhålls informations- och kommunikationstekniskt baserad vård som lösningen på denna utmaning (Hälsans nya verktyg (HNV) 2009-2011: 5). Med hjälp av IKT-baserat patientstöd kan vård och omsorg ges utanför traditionella vårdinstitutioner som sjukhus, ålderdomshem och gruppboenden. Vård och omsorg i hemmiljö beskrivs som en både kostnadseffektiv och kvalitetshöjande åtgärd (HNV 2009-2011: 14), och med hjälp av virtuella vårdplatser, distribuerad diagnostik och konsultationer ska läkare kunna ställa diagnos, rekommendera behandling och följa upp behandlingsresultat på distans. På den virtuella vårdavdelningen kan flera specialister vara engagerade $\mathrm{i}$ en patient samtidigt, vilket kan förkorta väntetider (HNV 2009-2011: 12) och förbättra behandlingen av äldre patienter med komplexa sjukdomsbilder. I dagens sjukvård träffar dessa patienter vanligtvis flera olika specialister som behandlar symtom inom respektive expertområde, utan en helhetssyn på patienten. Med en mer sammantagen bild av patientens behov ökar chanserna att rätt insatser sätts in.

En rad olika IKT-baserade lösningar för vård och omsorg erbjuds redan i dag. Kontroll och uppföljning av vårdtagares hälsa och allmäntillstånd bedrivs i hemmiljö med hjälp av Internet, mikrochips, mobiltelefoner och sensorer. Sådana lösningar lanseras ofta som alternativ eller komplement till traditionell sjukhusvård, i synnerhet för vård av kroniskt sjuka eller handikappade personer. Med hjälp av IKT-baserat vårdstöd kan människor som behöver kontinuerlig tillsyn fortsätta att bo på egen hand längre, och behöver kanske inte särskilt boende förrän längre fram i tiden. 
Samtidigt som tekniken kan medge ökad trygghet och självständighet (Socialstyrelsens årliga lägesrapport, 2010) innebär den att personspecifik och potentiellt integritetskänslig information överförs från vårdtagarens hem till en vårdenhet. Den information som samlas in kan lagras, bearbetas och samköras med annan information. Även om det primära syftet är tillsyn och stöd har IKT «minne» och kan därmed potentiellt användas för att övervaka personer. Det finns därför skäl att diskutera under vilka villkor, om alls, tekniken bör införas och det bör göras på ett tidigt stadium, innan den hunnit befästas. Syftet med den här artikeln är att ge en överblick över framväxande IKT-baserade hjälpmedel för hälsotillsyn i hemmet och att belysa etiska frågeställningar och problem som de ger upphov till. En sådan inventering kan bidra till att identifiera krav som bör ställas på tekniken.

\section{Distribuerad vård och omsorg}

Det påtalas ofta att vi behöver utveckla en vårdstruktur som är bättre rustad än den nuvarande att möta följderna av en åldrande befolkning. På EU-nivå betonas vikten av satsningar på e-hälsa, det vill säga informations- och kommunikationsteknik som kan användas för att ställa diagnoser, bistå behandling och för att följa upp och utvärdera patienters hälsotillstånd på distans. ${ }^{3}$

Med hjälp av IKT-baserade vårdlösningar kan vårdpersonalen kontrollera och följa upp vårdtagaren och dennes hälsotillstånd samtidigt som vårdtagaren kan bli mer delaktig i vårdprocessen. ${ }^{4}$ Inom omsorgen är tekniken tänkt att hjälpa gamla och funktionshindrade människor som behöver kontinuerlig vårdkontakt att fungera och känna trygghet i sin hemmiljö så länge som möjligt. Tekniken ska även hjälpa anhöriga att i större utsträckning ta aktiv del i den vardagliga omsorgen av den vårdbehövande, trots geografiska avstånd.

Men IKT-baserade vårdlösningar är inte enbart avsedda att erbjudas sjuka, handikappade eller gamla, utan även friska personer kan använda tekniken, i ett preventivt syfte. Genom att kontinuerligt mäta och registrera olika vitala funktioner och värden kan friska människor få bättre kunskap om sitt hälsotillstånd. Kvalificerade diagnostiska metoder för hemmabruk ska hjälpa friska personer att ta större ansvar för sin hälsa och följa upp sitt hälsotillstånd över tid. Kontinuerliga tester av till exempel hjärta, lungor och stresstillstånd kan snabbt visa när det uppstår avvikelser från de egna normalvärdena (HNV 2009-2011: 1). Om det leder till att människors behov av att uppsöka vårdinrättningar minskar kan primärvården avlastas. 


\section{Patientcentrerade, integrerade informationssystem för hemsjukvård och äldreomsorg}

Sensorteknik är på frammarsch inom ett stort antal tillämpningsområden och många förutspår att den kommer att påverka samhället i lika hög grad som Internet. Tekniken beskrivs med termer som «ambient ...», «ubiquitous ...» eller «pervasive computing» termer som är mer eller mindre synonyma men har olika tillkomsthistorier. ${ }^{5}$ Den gemensamma nämnaren är tekniska system som erbjuder informations- och kommunikationstjänster med hjälp av sensorer som är inbyggda i infrastruktur och vardagsföremål och därifrån kommunicerar med en databas. Miljöer och föremål kan göras «smarta» genom att «fysiska objekt kopplas elektroniskt till den digitala världen» (Datainspektionen 2007). Dessa kan programmeras att assistera användaren utan att denne aktivt efterfrågar assistans. Tekniken möjliggör också automatisk identifiering och lokalisering av människor, djur och objekt. Sensorerna registrerar och läser av sin omgivning utan att synas. Det sammantagna resultatet är allestädes närvarande tjänster som är anpassade efter beställarens/användarens önskemål. I framtiden förutspås IKT vara fullständigt integrerad med tjänster som är tillgängliga överallt med hjälp av «smart dust», det vill säga mikrosensorer som läser av och samlar in information som den sedan rapporterar och kommunicerar med sin omgivning (Kosta, Pitkänen, Niemelä \& Kaasinen 2009).

Inom vården används sensorteknik för medicinsk övervakning och diagnostisering. Inbyggda i kläder och klockor eller inopererade under huden kan sensorer läsa av en mängd hälsorelaterade parametrar som kroppstemperatur, syrehalt i blodet, hjärtrytm och blodtryck, och sedan vidarebefordra data till vårdgivaren (Otto, Jovanov \& Milenkovic 2005). Mikrosensorer kan byggas in i golv och väggar för att registrera och larma om vårdtagaren faller men även om hon inte rör sig $i$ hemmet under en viss tid. De kan också rapportera om dörrar eller fönster står öppna eller om spisplattor eller strykjärn står på. Ett område som är under utveckling är smarta textilier, en samlingsbeteckning på interaktiva textila material som knutna till ett datorsystem kan läsa av och reagera på faktorer i omgivningen i ett visst syfte (Jul 2008). Textilier med invävda sensorer som kan registrera biosignaler kommer att kunna registrera hjärtrytm och andning hos hjärtpatienter och slå larm vid oregelbundenheter. Forskning bedrivs även på sensorer som kan läsa av biomarkörer och signalera vävnadsskada, exempelvis för att förhindra att trycksår uppkommer. Sensorerna ska integreras i föremål som kommer i kontakt med patientens hud, som kläder, bandage, lakan eller madrasser. Om en sängliggande patient inte rör sig tillräckligt ofta ska sensorerna aktivera en mekanisk rörelse i sängen som hjälper patienten att inta en ny, tryckavlastande position (HNV 2009-2011:29).

Inom sjukvården förekommer, förutom biologiska implantat, även mikrosensorimplantat. Kokleaimplantat exempelvis stimulerar den akus- 
tiska nerven i örat vilket gör att döva och gravt hörselskadade kan höra (Wass 2009). Implanterbara defibrillatorer och pacemakers används för att övervaka och återställa bärarens hjärtrytm. En defibrillator som kontinuerligt övervakar hjärtats rytm kan upptäcka och häva en rubbning av hjärtfrekvensen med hjälp av en elektrisk stöt. Forskning bedrivs även på möjligheten att med hjälp av implantat stimulera nervsystemet för att behandla symtom på sjukdomar som parkinson och alzheimer men även vissa neuropsykiatriska sjukdomar som tvångsmässiga beteenden (Hildt 2006).

Sammanfattningsvis är sensorer tänkta att integreras i väggar, inredning, kläder, bruksföremål och till och med i oss själva för att obemärkt assistera oss i vardagslivet. Fördelar som framhållits med sensorteknik i vård och omsorg är att den möjliggör smidig, kontinuerlig mätning och diagnostisering av vitala funktioner och snabb respons på larm inom hemsjukvård. I och med den elektroniska överföringen av hälsodata behöver inte vårdtagare uppsöka ett sjukhus eller en vårdcentral för att få sina värden mätta. Bärbara sensorer innebär att patienten slipper vara uppkopplad mot mätapparatur och lämpar sig på så vis för hemsjukvård. ${ }^{6} \mathrm{Om}$ värden avviker från normalvärdena kan larm till vårdgivare eller anhörig aktiveras. Men låt oss nu se på de etiska implikationerna av sensortekniken utifrån en distinktion mellan extern och intern sensorteknik. Extern sensorteknik definieras här som sensorer i kläder, utrustning och boendemiljöer, medan intern sensorteknik är olika typer av implantat.

\section{Etiska implikationer av extern sensorteknik}

Sensorbaserade vårdlösningar som är utvecklade för sjukvård och omsorg i hemmet innebär att övervakningskapabel teknik flyttar in i hemmiljö. De flesta människor är nog benägna att se platsen där man bor som en sfär där man har rätt att vara fri från intrång och insyn. Genomgripande sensorteknik innebär ett intrång i denna uppenbart privata sfär. Larm knutna till sensorerna kan också upplevas som integritetskänsliga. När något händer larmas en vårdgivare och/eller en anhörig. Vårdtagaren kan uppleva det som pinsamt att systemet slår larm till en anhörig. Det kan även vara integritetskänsligt, beroende på relationen mellan vårdtagare och anhörig. Sensorer med larmfunktion kan också användas av paternalistiska skäl, för att förhindra att vårdtagaren utför handlingar som kan innebära en viss risk (Sharkey \& Sharkey 2010), i sämsta fall utan respekt för att vårdtagare liksom människor i allmänhet är mer eller mindre benägna att ta eller undvika risker.

Bärbar sensorteknik som läser av olika hälsoparametrar genererar också personspecifik och potentiellt integritetskänslig information. Informationssäkerhetsregler kräver att endast behöriga personer får tillgång till informationen och att den sekretesskyddas vid överföring, lagring och behand- 
ling. Att informationen hanteras korrekt är avgörande för användarens förtroende för tekniken. Externa sensorer genererar också information som kanske inte är av uppenbart integritetskänslig natur, men som ändå bör hanteras med försiktighet. Rörelsekänsliga sensorer i vårdtagarens väggar och golv medför att vårdpersonalen kan följa dennes vardagliga förehavanden, som när vårdtagaren stiger upp och lägger sig, hur ofta hon öppnar kylskåpet, lagar mat, duschar, besöker toaletten, när hon har besök etc. Om den sensorgenererade informationen lagras och analyseras samlat kan tämligen komplexa kartor över vårdtagarens vanor och beteendemönster extraheras. Även om den information som lagras inte uppfattas som integritetskänslig $i$ sig själv kan den komma att upplevas som känslig som en sammantagen bild. En person kan samtycka till att information a, b och $\mathrm{c}$ registreras var för sig men kanske inte till den sammantagna effekten av $a+b+c$ (Palm 2005). En risk som uppstår i och med övervakningen kan även vara att patienten börjar agera i sitt hem som hon tror att det förväntas av henne, snarare än på det sätt som hon själv önskar leva sitt liv.

En hittills tämligen ouppmärksammad aspekt av den nya tekniken är hur människor påverkas av att ständigt uppdatera sig själv eller vårdgivaren om det egna hälsotillståndet eller om parametrar som är centrala för hälsan. Den individanpassade vården kan innebära ett skifte i synen på patienten från en passiv mottagare av vård till en välinformerad och i vårdprocessen aktivt engagerad vårdtagare. Med kunskap om hur till exempel blodtrycket påverkas av kost, motion och medicin kan patienten formulera sina egna mål och ta makt över sitt eget liv.

Å andra sidan kan en situation där man ständigt förväntas kontrollera det egna hälsotillståndet leda till en medikalisering av vårdtagarens identitet, där hon primärt förstår och definierar sig själv i termer av sin ohälsa eller hälsa, och som patient. Det finns en risk att patientrollen kommer att dominera vårdtagarens självuppfattning. Utifrån ett vidare perspektiv på hälsa är rutinmätningar inte med nödvändighet hälsofrämjande (Collste kommande).

I takt med att vårdtagare får tillgång till tekniska resurser för att kontinuerligt kontrollera sitt hälsotillstånd och faktorer som påverkar hälsan och på vilket sätt, kan det hända att läkares och vårdpersonals attityder till livsstilsrelaterad ohälsa förändras och att acceptansen för den sänks. Kost- och motionsvanor, till skillnad från genetiska förutsättningar, ligger ju inom ramen för vad individen kan påverka.

\section{Etiska implikationer av intern sensorteknik}

Vilka etiska implikationer kan då bruket av sensorer $i$ kroppen ge upphov till? Enligt en något grovmaskig uppdelning kan man skilja mellan implantat som är avsedda att (1) identifiera en person, (2) diagnostisera/följa upp 
ett biologiskt tillstånd (3) återställa eller reparera funktioner hos personer och (4) förbättra en persons minne, syn, hörsel eller reaktionsförmåga (Kosta \& Gasson 2008).

Implantat försedda med radiofrekvenssändare/-mottagare kan läsas av på distans och användas för att identifiera var vårdtagaren befinner sig och kartlägga hennes rörelser. I framtidens «smarta hem» där sensorläsare finns integrerade i väggar, golv, möbler och vardagsföremål kommer vårdtagare med implantat att kunna identifieras, läsas av och kontrolleras kontinuerligt.

En fördel med ID-implantatet är att det är knutet till bäraren på ett beständigt sätt, vilket kan underlätta för demensvården. I dag bär dementa patienter ofta med sig larm som är kopplade till vård- eller servicecentraler, men det är inte alltid som bäraren kommer ihåg att ta på sig larmet (Essén 2008). Ett ID-implantat med larmfunktion skulle alltid vara på plats. Inom demensvård är det viktigt att i möjligaste mån låta vårdtagarna röra sig fritt och samtidigt garantera att de inte förirrar sig (Welsh, Hassiotis, O’Mahoney \& Deahl 2003). Oftast används olika typer av lås, exempelvis på gruppboenden för senildementa patienter, för att förhindra att de dementa patienterna lämnar området. Låsen kan dock begränsa friheten för andra vårdtagare som inte är demenssjuka. Med hjälp av RFID-implantat med larmfunktion kan man låta dörrar på gruppboenden vara olåsta och de demenssjuka kan få röra sig fritt, samtidigt som vårdgivaren kan ha kontinuerlig tillsyn.

En viktig aspekt på vård och omsorg är att agera med respekt för vårdtagarens värdighet. Det handlar dels om att behandla patienten som den unika person hon är, inte som en i den stora mängden av vårdtagare, dels om att vara lyhörd för hennes önskningar och preferenser. Det har hävdats att implantat är ovärdigt vårdtagare och socialt stigmatiserande, eftersom det traditionellt använts på djur och kriminella (O’Neill 2003). Men implantat kan tillgodose vårdtagarens specifika behov och stärka dennes värdighet genom att exempelvis förhindra att hon förirrar sig, vilket kan vara både traumatiskt och ovärdigt för en demenssjuk människa. En svårighet är dock för vårdpersonal att få ett informerat samtycke från demenssjuka patienter för vilka implantat skulle kunna innebära säkerhetsmässiga fördelar. Enligt en vanlig uppfattning inom medicinsk etik kan dock sensorbaserade larm implementeras för den demenssjukes bästa, utan att patienten har gett ett fullständigt informerat samtycke (Mahoney 2007).

En aspekt som förtjänar uppmärksamhet är att mikrochipset i implantatet kan registreras och läsas av utan att bäraren är medveten om detta. Det är alltså inte bara betydelsefullt vilken typ av information som finns registrerad på chipset, utan också hur den hanteras. Om den information som är registrerad i implantatet motsvarar data som vanligtvis finns på ett patientkort och läses av av vårdpersonal i direkt kontakt med bäraren finns det 
ingen uppenbar, etiskt relevant skillnad mellan patientkort och ID-implantat. Möjligheten att läsa av implantatet utan bärarens vetskap har dock etiska implikationer, eftersom det påverkar hennes möjligheter att kontrollera hur informationen används och vem som vet vad om henne etc. På så sätt begränsas vårdtagarens kontroll över den egna personen.

För en hjärtsjuk person kan det vara tryggt med en bärbar sensor som indikerar det egna hälsotillståndet och som slår larm vid oregelbundenheter i hjärtrytmen. Den kontinuerliga mätningen av hjärtrytmen kan ge vårdtagaren en känsla av ökad kontroll. Samtidigt kan rutinövervakningen generera en mer komplex och möjligen känsligare bild av vårdtagarens hälsotillstånd än enskilda mätningar spridda över tid, och eftersom implantatet är intimt och beständigt knutet till bäraren påverkas den personliga integriteten på ett speciellt sätt. Ett implantat som är inopererat i personen påverkar den fysiska/kroppsliga integriteten. Ytterligare frågor väcks av att forskare arbetar på att utveckla neuroimplantat som kan stödja nervsystemet och hjärnan. En sådan teknik skulle kunna få följder för beslutsintegriteten. Om hjärnan stimuleras på artificiell väg av implantat, i vilken utsträckning kan bäraren då sägas vara autonom? (Rodota \& Capurro 2005).

Implantat kan påverka kroppen, dess karaktär och möjligheter, och viss sensorteknik kan tjäna till att återställa förlorade biologiska funktioner. Olika sorters proteser, artificiella leder, defibrillatorer och pacemakrar kan kompensera för eller återställa en förlorad funktion. Implantaten kan användas både för medicinska ändamål och för att förbättra eller förstärka kroppen eller kroppsliga funktioner. Det är dock inte alltid lätt att skilja mellan att reparera och förbättra, och vad man lägger in i respektive begrepp. Den svårigheten illustreras exempelvis av schismen mellan läkare som förordat kokleaimplantat (cochlea implant, CI) och dövas intresseorganisationer (Reuzel 2004; Sandel 2007). Det kliniska perspektivet har varit att dövhet är en defekt som kan avhjälpas, medan de döva har argumenterat att dövhet är ett karaktärsdrag, att döva utgör en minoritet med ett eget språk - teckenspråket. De döva har värjt sig mot skälen för och den «korrigering» som implantaten innebär (Reuzel 2004). På sikt är det möjligt att det uppstår diskriminering där de som inte «förbättras» blir relativt sett underlägsna och möjligen exkluderade från vård för att de valt att inte «förbättra» vissa förmågor och därför kräver mer stöd eller resurser. Vårdtagaren kanske nekas annan vård eller hjälp för att hon valt att avstå från tekniken.

Möjligheten att med hjälp av elektroder som förs in i ett område i hjärnan dämpa signalerna till nerverna och därmed påverka en persons fysiska eller kognitiva förmåga väcker frågor om reversibilitet. Kan denna påverkan återställas eller är den permanent? (Fischer Hübner 2008). Vidare kan gränser för den fysiska kroppen, i viss mening, komma att suddas ut i och med 
att implantaten är datorstyrda. I förlängningen är det inte bara implantaten som är avgörande för bärarens hälsa och välmåga utan de tekniska system eller artefakter till exempel datorer som möjliggör deras funktion i kroppen. En relevant fråga blir huruvida kroppsuppfattningen och synen på rätten till den egna kroppen förändras när vissa delar i kroppen inte är «naturligt givna»? (van der Ploeg 2005). Och hur bör detta förstås när delar av kroppen ersätts med icke-biologiska delar, som ett artificiellt hjärta? (Kosta \& Gasson 2008).

\section{Kameraövervakning}

Övervakning av det offentliga rummet har diskuterats intensivt det senaste decenniet. Ett relativt nytt tillämpningsområde som behöver genomlysas är kameraövervakning i vård och omsorg.

Flera svenska kommuner är på väg att införa kamerasystemet «Nattpatrullen» i den hembaserade äldrevården. ${ }^{7}$ Nattpatrullen är en mörkerseende kamera som installeras i sovrummet hos vårdtagaren, så att hemtjänstpersonalen kan se till vårdtagaren när som helst under natten. Om vårdtagaren slår larm kan hemtjänstpersonalen med kamerans hjälp bedöma hur akut vårdtagarens behov av assistans är. Möjligheten till mer frekvent tillsyn kan förhindra att vårdtagare som fallit ur sängen blir liggande på golvet under lång tid. Parterna kan också kommunicera via kameran.

Tekniken har godkänts av Socialstyrelsen och teknikutvecklaren Myjoice $^{8}$ framhåller fördelar som minskade kostnader för kommunen, möjligheten för vårdgivaren att bedriva tätare kontroller och att vårdtagaren inte behöver bli störd i sömnen av att hemtjänsten «klampar in och tänder i hallen» på natten. Framför allt är tekniken avsedd att göra så att personalen kan se till vårdtagarna oftare och att personalresurserna samtidigt kan användas mer effektivt. Genom möjligheten att göra virtuella besök kan vårdtagaren få direkt assistans när hon faktiskt behöver den, hon kan slippa onödiga hembesök och personalinsatserna kan kanaliseras till de vårdtagare som bäst behöver fysisk tillsyn och assistans. Kamerasystemet Nattpatrullen lanseras som ett frivilligt komplement till vanliga hembesök.

Tillsyn med hjälp av ett videobaserat kommunikationsmedel som Nattpatrullen möjliggör inte bara tätare virtuella vårdkontakter utan även tillsyn överhuvud av vårdtagare i avlägsna delar av landet. Tekniken kan på så sätt kompensera för geografiska avstånd. Sedd ur ett rättviseperspektiv kan tekniken bidra till en jämnare fördelning av vårdtillsyn. Men hur påverkar den här typen av vårdstöd kvaliteten på vården?

IKT-baserad vård kan tas emot positivt av vårdtagare (Sävenstedt 2004), men tekniken kan även komma att användas för att spara pengar. I förlängningen kan kommuner skära ner antalet hembesök, vilket skulle göra många äldre isolerade. Om vårdgivaren skulle anställa fler personer till 
hemtjänsten för att kunna ge äldre som behöver vårdstöd tätare tillsyn skulle det rimligen uppfattas som en vårdkvalitetshöjande åtgärd, men gäller detsamma för tätare virtuell tillsyn? Tekniken kan innebära en trygghet för vårdgivare, vårdtagare och anhörig, men kan den tillgodose säkerhet? Kameratekniken inkräktar dessutom på vårdtagarens personliga integritet eftersom kameran opererar i hemmets mest uppenbart privata sfär.

\section{Robotar i vård och omsorg}

Robotteknik för vård och omsorg är ett expansivt område. Sjuksköterskeroboten Flo påminner patienter om att ta sin medicin, mäter vitala funktioner och rapporterar hälsodata via mejl till en databas. ${ }^{9}$ Roboten Bestic fungerar bokstavligen som en förlängd arm och hjälper funktionsnedsatta personer att äta utan hjälp av vårdpersonal. ${ }^{10}$ Smarta exoskelett (robotskelett), i form av dräkter med armskenor, utvecklas för att skydda och stärka vårdpersonal som utför tunga lyft och minimera risken för förslitningsskador. ${ }^{11}$ Roboten Robocab avlastar vårdpersonal från tunga sysslor genom att bära sängkläder och bädda sängar. ${ }^{12}$ I det följande diskuteras etiska implikationer av två specifika tillämpningar av robotteknik roboten Giraffen och robotsälen Paro.

\section{Roboten Giraffen}

Giraffen $^{13}$ är en fjärrstyrd och mobil robot med bildskärm och kamera som kommer att användas inom hemsjukvård för att underlätta för sjukvårdspersonal, släkt och vänner att kommunicera trots avstånd. Den är också tänkt att öka handikappades självständighet och oberoende. Till skillnad från andra visuella kommunikationsmedel kan Giraffen söka upp och följa efter vårdtagaren $\mathrm{i}$ hemmet. Teknikutvecklaren lanserar Giraffen som ett frivilligt komplement till det befintliga vårdutbudet, för att öka tryggheten för vårdgivare, vårdtagare, anhörigvårdare och anhöriga. Inom traditionell hemtjänstvård upprättar vårdtagare och vårdgivare ett avtal för hur vården ska bedrivas (antal hembesök, vid vilka tillfällen och under vilka villkor vårdpersonalen har rätt att gå in i vårdtagarens hem med nyckel). På samma sätt klargörs ramarna för den robotbaserade vården. Man kan till exempel komma överens om att vårdpersonalen får rätt att se till vårdtagaren med hjälp av Giraffen om denne inte svarar när vårdpersonalen ringer. Utgångspunkten är givetvis att kommunikationen mellan vårdpersonal och vårdtagare via roboten ska vara ömsesidig.

Även om tekniken kan innebära en ökad trygghet för vårdtagare, anhörigvårdare och anhöriga finns risken att tekniken, i förlängningen, kan komma att ersätta människor. Liksom Nattpatrullen möjliggör Giraffen tätare virtuella kontakter, vilket kan minska antalet fysiska vårdbesök och 
möten mellan vårdpersonal och vårdtagare. Men är en sådan utveckling etiskt problematisk, och i så fall på vilket sätt?

AI-baserad vård (AI = artificiell intelligens) har kritiserats för att vara kvalitativt sämre än vård och omsorg som utförs direkt av vårdpersonal av kött och blod, av det skälet att det känslomässiga utbytet mellan vårdpersonal och vårdtagare uteblir (Sparrow \& Sparrow 2006). Inom vårdetiken betonas vikten av att vårdrelationen karaktäriseras av tid, kontinuitet, närhet, empati (Holm 1987), tillit och förtroende (Martinsen 1991). Förvisso förmår inte $\mathrm{AI}$ att ge vård med empati, men det kan hävdas att den traditionella vården inte heller alltid lever upp till det kravet. Det finns inte alltid närhet $\mathrm{i}$ relationen mellan vårdpersonal och vårdtagare inom det rådande vårdsystemet (Coeckelberg 2010). Vårdpersonalen har ofta ett stort antal patienter att assistera och många av uppgifterna utförs på rutin. Det är inte alltid möjligt för vårdpersonalen att ha ett djupare känslomässigt engagemang (en viss distansering kan vara nödvändig). Att den traditionella vården inte alltid lever upp till vårdidealet är dock inte ett särskilt bra skäl för att ersätta «manuell vård» med robotar, utan snarare ett skäl för att förbättra vårdpersonalens förutsättningar för att ge högkvalitativ vård.

Men om tekniken kan få oss att uppleva något som är ett viktigt mål för vården, som lycka eller välbefinnande finns det då någon moraliskt relevant skillnad (och i så fall vilken) mellan lycka eller välbefinnande som genererats av manuell mänsklig vård och teknikassisterad eller virtuell vård? Med hjälp av Nozicks lyckomaskinsexempel diskuterar Mark Coeckelberg etiska implikationer av den virtuella vården. Om vi fick välja mellan att själva styra våra liv och att låta neuropsykologer koppla ihop oss med en maskin som genererar lyckoupplevelser i oss menar Nozick att vi skulle välja det reella livet i stället för det virtuella (Coeckelbergh 2010). Lyckoupplevelserna i maskinen är inte lika värdefulla som upplevelser som är knutna till våra egna val och handlingar, eftersom det är genom dessa vi konstituerar oss själva, skapar mening, etablerar relationer etc. Vägen till välbefinnandet är betydelsefull i sig.

Teknikutvecklaren påpekar dock att syftet med Giraffen är att komplettera och assistera snarare än att ersätta mänskligt arbete vid behov av kontinuerlig tillsyn. Förhoppningen är att tekniken ska frigöra tid från rutinuppgifter till förmån för kvalitetstid med patienter och därmed främja snarare än motverka mellanmänskliga relationer och närhet.

\section{Robotsälen Paro}

Paro är en avancerad robot i form av en mjuk liten sälkut, som utvecklats som sällskapsdjur att användas inom vård och omsorg. Sälroboten är utrustad med sensorer, vilket gör att den kan interagera med sin omgivning. Den känner av hur man klappar och håller den, sensorer styr dess rörel- 
semönster och reagerar på beröring. Paro är inte bara mjuk och gosig utan är försedd med ett element som avger «kroppstemperatur». Trots att man har påvisat positiva effekter av att ha levande sällskapsdjur såsom hund och katt på vårdavdelningar är detta oftast en omöjlighet av allergi- och tillsynsskäl (Banks \& Banks 2002). Till skillnad från levande djur behöver inte Paro rastas och skapar inte allergier. Småskaliga studier indikerar att både sjuka barn och äldre reagerar mycket positivt när de klappar och pratar med Paro dels när patienterna själva skattar hur de mår, dels när man mäter mängden stresshormoner i blodet och studerar deras sociala samspel. Det har också noterats att de beter sig som om Paro vore ett riktigt djur. ${ }^{14}$

Samma kritik som riktats mot AI-baserad vård kan drabba den här typen av «omsorgsresurs» - att den inte kan tillgodose aspekter som är centrala för vården, som empati och ömsesidighet. Dessutom har den här typen av robotteknik kritiserats för att utge sig för att vara något som den inte är och för att föra vårdtagaren bakom ljuset (Sparrow \& Sparrow 2006). Om vårdtagaren upplevde Paro som en bluff kunde det naturligtvis påverka hennes förtroende för vårdgivaren negativt. Huruvida Paro upplevs som en bluff eller inte beror rimligen på hur den introduceras av vårdgivaren. Roboten kan introduceras (1) som ett substitut för kvalificerat sällskap (vårdpersonal), (2) som kompensation för de husdjur som man av praktiska skäl inte kan ha på vårdcentralen eller (3) som ren förströelse (komplement). Om den används för att ersätta kontakten med vårdpersonal är kritiken av Paro rimligen berättigad. Även om vårdtagaren upplever välbefinnande av att kela med Paro skulle hon förmodligen föredra personlig kontakt med vårdpersonal som hon känner, som bryr sig om, lyssnar på och rör vid henne (Sharkey \& Sharkey 2010). Om den används som ett sätt att bemöta ett behov som inte kan realiseras på naturlig väg eller som ett komplement till ordinarie omsorg förefaller Paro dock inte vara uppenbart etiskt problematisk.

Den avgörande frågan för teknikens etiska berättigande verkar återigen vara huruvida tekniken ersätter/reducerar mellanmänskliga kontakter och manuell vård eller om den utgör ett komplement till sådan vård.

\section{Vårdetiska principer och IKT}

Centrala principer inom medicinsk etik och vårdetik är principerna om godhet, om att icke skada samt om autonomi och rättvisa (Beauchamp \& Childress 2001) liksom principen om informerat samtycke, som ska säkerställa autonomi och valfrihet. I det följande diskuteras några av de etiska aspekter som tangerats upprepade gånger; personlig integritet, valfrihet och informerat samtycke. 


\section{Personlig integritet}

Ett återkommande problem med de olika IKT-baserade vårdlösningarna är deras inverkan på den personliga integriteten, vilket motiverar en utförligare diskussion av det begreppet.

Att den personliga integriteten är viktig ifrågasätts sällan. Varför den är viktig och i vilken utsträckning den bör värnas råder det dock oenighet om. Vad som är integritetskänsligt sägs variera mellan kulturer, individer och över tid (Nissenbaum 2004; Anderson 2008). Den nakna kroppen anses ofta vara integritetskänslig i väst men till exempel inte i Japan. Information om nedsatt syn eller hörsel upplevs däremot som integritetskänslig i Japan men inte i väst (Adams, Murata \& Orito 2009).

Skäl för att skydda de aspekter som anses känsliga är bland annat respekt för individens odelbarhet, okränkbarhet och särart (definition av värdet av personlig integritet i Svenska Akademiens ordlista), autonomi (Scanlon 1975; Rössler 2005), intimitet (Inness 1994) och värdighet (Bloustein 1964). Somliga menar dock att vi bör undvika att reducera personlig integritet till endast ett sådant värde och i stället se hur integriteten är central för att säkra förslagen ovan men även andra värden som demokrati (Lever 2007). Det har också betonats att den personliga integriteten inte bör förstås enbart som ett individuellt utan också som ett kollektivt värde. Ett skydd för den personliga integriteten är nödvändigt för att medborgare ska våga uttrycka sina åsikter och utnyttja sina politiska rättigheter (Regan 1995). Den personliga integriteten är med andra ord en mångfacetterad företeelse. Filosofen Beate Rössler använder tre dimensioner för att ringa in centrala aspekter av den personliga integriteten; (1) beslutsrelaterad integritet, (2) informationsrelaterad integritet och (3) rumslig integritet (Rössler 2005). De olika typerna av IKT-baserat vårdstöd som tidigare diskuterats inverkar på samtliga dimensioner. Möjligen kan det vara relevant att se den fysiska integriteten som en separat dimension en fjärde dimension som uppenbart påverkas i vård och omsorg.

Att IKT-baserat vårdstöd har en integritetskränkande potential, är ett av de vanligaste argumenten mot den typen av teknik. Å andra sidan kan det hävdas att den personliga integriteten oundvikligen kommer i kläm när en person uppsöker vård, och att övervakningskapabla vårdfunktioner därför har en marginell inverkan. Den informationsrelaterade integriteten kommer i kläm i mötet med läkare och/eller vårdpersonal, där patienten måste uppge hälsorelaterad information som kan röra intima aspekter av personen och hennes privatliv. Personkänslig medicinsk information antecknas $i$ journaler, och informationen i patientjournaler har traditionellt ansetts känslig och skyddats med hjälp av sekretesslagen. Vid undersökningar är läkaren eller sköterskan dessutom oftast tvungen att röra vid patienten för att undersöka henne och ta prover etc. I hemsjukvård och omsorg assisterar vårdpersonalen vårdtagare $\mathrm{i}$ vardagliga sysslor, vilket kan inbegripa hjälp 
med toalettbesök och intimhygien. Även om den här typen av assistans är nödvändig innebär den ett visst intrång i den fysiska integriteten. Den beslutsrelaterade integriteten kan också komma att begränsas i fall där vårdpersonalen har svårt att få ett informerat samtycke från vårdtagaren. Vid vårdtillsyn i hemmet kommer ytterligare en dimension av den personliga integriteten att inkräktas på den rumsliga.

Vård och tillsyn kan med andra ord alltid begränsa den privata sfären, men patienten kan acceptera detta intrång för att säkerställa trygghet och kontinuerlig tillsyn. Det nämndes tidigare att den personliga integriteten är ett kontextuellt värde som skiftar över tid och rum. Hur mycket vårdstöd man behöver tycks vara en aspekt som påverkar hur man upplever den personliga integriteten. En viktig men otillräckligt undersökt fråga är hur personer med behov av stöd upplever den personliga integriteten. En del äldre personer hävdar att de inte ställer samma krav på personlig integritet som de gjorde tidigare eftersom de upplever sig själva som sköra och i behov av stöd och prioriterar säkerhet framför integritet (Essén 2008). När tekniken kritiseras för dess integritetskränkande aspekter är det inte med nödvändighet ur användarens perspektiv.

Teknikens inverkan på den personliga integriteten bör dock inte enbart vägas mot de positiva värden den kan främja i termer av trygghet och säkerhet, utan även mot dess möjligheter att skydda vissa dimensioner av den personliga integriteten. IKT-baserad vårdteknik kan vara både integritetskränkande och integritetsfrämjande, eftersom den personliga integriteten rymmer en rad olika dimensioner.

Även om IKT-stöd i hemvård innebär att övervakningskapabel teknik flyttar in i hemmet och att den rumsliga integriteten kränks kan hemvården undvika integritetskänsliga aspekter som ofta aktualiseras i sjukhusvården. Empiriska studier har exempelvis visat att patienter upplevt kränkningar av den egna integriteten i vården när de varit tvungna att dela rum med andra patienter (Marini 1999; Mattiasson \& Hemberg 1998; Woogara 2005), men även att de reagerat negativt på att lyssna på samtal mellan läkare och patienter de delat rum med (Sidenvall, Fjellström \& Ek 1994). Det har konstaterats att patienter verkar vara mer intresserade av integritetsskydd gentemot andra patienter än gentemot läkare och vårdpersonal (Essén 2008). ${ }^{15}$ Det bör också noteras att vårdtagaren i vissa sammanhang kan uppleva en fördel av att tillsynen sköts av en robot än av hemtjänstpersonal, till exempel som stöd vid intimhygien och toalettbesök. Vårdtagarens fysiska integritet och värdighet kan med andra ord stärkas med hjälp av IKT-stöd.

Oavsett om äldre personer tenderar att prioritera trygghet över integritet är den personliga integriteten ett viktigt värde och teknikens integritetskränkande följder bör minimeras så långt som möjligt (Palm 2005). När det gäller allmän övervakning i det offentliga rummet är det av avgörande betydelse att händelser registreras men inte att individer identifieras. Iden- 
tifiering blir nödvändig först vid tillbud. Personer kan följas via kameror utan att övervakaren ser vem det är. Det filmmaterial eller de foton som automatiskt tas när en person kliver in i en svensk taxibil krypteras och blir endast tillgängliga för behöriga parter om det händer något som leder till polisanmälan. När det gäller övervakning av en vårdtagare i dennes hemmiljö är det dock svårare att avidentifiera övervakningsobjektet. I det fallet är övervakningen knuten till en på förhand registrerad identitet. Dessutom kan överskottsinformation samlas, exempelvis genom att anhöriga direkt eller indirekt blir föremål för övervakning. Trots detta går det att minimera teknikens integritetskränkande effekter genom att (1) vara lyhörd för vilken typ av information man hanterar, (2) endast samla in just den mängd information som behövs och (3) endast lagra och vidarebefordra data om det är nödvändigt. Vidare kan vårdgivaren välja att i möjligaste mån använda sig av icke-identifierande övervakningsteknik som ljus- och rörelsesensorer och trampmattor, snarare än identifierande kameror.

\section{Frivillighet}

I vilken utsträckning kan den individanpassade hälsokontrollen anses vara frivillig? Övervakning antas ofta stå i motsättning till frivillighet, men ett exempel på frivillig övervakning kan vara när personer självmant väljer att registrera information om sin hälsa på nätverkssajter som «The Quantified Self» och «Cure together» ${ }^{16}$. Dessa är exempel på nätverksgrupper där användare bygger profiler och delar med sig av det egna hälsotillståndet och tar del av andras dito i syfte att hitta lösningar på symtom och åkommor där den traditionella vården gått bet. Förmodligen upplever den här gruppen av «hälsoövervakare» att de själva kontrollerat den information de delger andra och de motiveras antagligen av förväntad personlig vinning. De förefaller dessutom vara relativt IKT-vana personer vilket inte med nödvändighet är sant om andra kategorier av vårdtagare. Men hur förhåller det sig med det IKT-baserade vårdstöd som exemplifierats tidigare i texten? Oftast framhåller teknikutvecklare och vårdgivare att den här typen av vårdlösningar endast är komplement till den rådande vårdformen. Vårdtagaren kan frivilligt välja IKT-baserade vårdtjänster, som Nattpatrullen, utöver ordinarie tjänster. Men givet att dessa vårdlösningar (1) medför de säkerhets- och bekvämlighetsvinster och (2) är så effektiva och kostnadsbesparande som teknikutvecklarna förespråkar är det inte orimligt att anta att de på sikt kan komma att utgöra standardformen för vård. Givet en sådan utveckling, i vilken utsträckning bör vårdgivaren tillmötesgå vårdtagare som efterfrågar resurskrävande vårdalternativ som personlig assistans i stället för kameramedierad sådan av integritetsskäl? I en värld av obegränsade resurser behövde inte frågan ställas, men utifrån rådande ekonomiska begränsningar där prioriteringar är nödvändiga blir den relevant. 
Vårdtagarens anspråk på en mer resurskrävande vårdform av den totala vårdkakan inverkar (åtminstone indirekt) på andra vårdtagares möjligheter och valalternativ. I takt med att det IKT-baserade vårdstödet ökar kan integritetsskydd komma att bli en exklusiv preferens inom vård och omsorg.

\section{Informerat samtycke}

Vård och omsorg ska bedrivas med respekt för vårdtagarens autonomi. Med personlig autonomi menas vanligen självständighet, självstyre och självbestämmande. Genom att respektera en persons självbestämmanderätt $\mathrm{i}$ beslut som berör henne respekterar man personens autonomi. Hennes självbestämmande begränsas dock av andras lika rätt till att själva styra sina liv. Informerat samtycke är ett verktyg för att garantera patienten valfrihet och värna hennes autonomi. Ett avtal om en medicinsk behandling mellan vårdgivare och vårdtagare är moraliskt och juridiskt försvarbart först när vårdtagaren samtyckt. För att hennes samtycke ska vara ett informerat samtycke krävs att hon fătt nödvändig och relevant information från vårdgivaren, att hennes valmöjligheter presenterats på ett sakligt och neutralt sätt och att hon inte utsatts för otillbörlig påverkan. Informationen ska även ha kommunicerats på ett sätt sådant att (den beslutskapable) vårdtagaren kunnat tillgodogöra sig den. Vårdtagaren ska även ha möjligheten att dra sig ur ett vårdprogram. För att ytterligare skärpa kravet på informerat samtycke kan hävdas att man bör differentiera mellan (1) att ha tillgång till information, (2) att ha kunskap om vad informationen betyder och (3) att kunna använda sig av informationen, till exempel basera beslut på den. Det senaste kriteriet bör vara uppfyllt för fullvärdigt samtycke. Vidare kan det finnas skäl till att analysera bakgrundsfaktorer som kan påverka patientens samtycke (Peter 2004). Man talar exempelvis om implicit tvång. I Sour grapes - Studies in the Subversion of Rationality (Elster 1983) diskuterar Jon Elster preferensadaption. Han argumenterar att individers preferenser kan komma att formas utifrån vad de upplever vara realiserbara önskningar (Elster 1985). I likhet med fabelns räv som bestämmer sig för att druvorna som han inte når säkert ändå smakar surt, kan vårdtagaren omedvetet reducera värdet av det hon egentligen skulle ha önskat om det inte hade verkat så svårt att realisera. Om vårdtagaren är medveten om att det intuitivt mest tilltalande vårdalternativet $\mathrm{X}$ (personliga och täta hembesök) är mycket resurskrävande, kanske hon förmodar att vårdgivaren föredrar att hon väljer det mindre resurskrävande alternativet Y (Nattpatrullen) framför X. Vårdtagaren kan omedvetet komma att tona ned sina integritetsanspråk i situationer där det verkar vara svårt att få gehör för den typen av krav. Ett motargument skulle kunna vara att det är de preferenser vi ger uttryck för som bör räknas och att det i detta exempel är vårdtagarens över- 
ordnade preferens att «inte vara vårdsystemet till last». Men vården syftar till att verka i vårdtagarens intresse och preferensen «att inte vara till last» är inte ett rimligt intresse. ${ }^{17}$ För att undvika den här typen av preferensjustering är det viktigt att vårdgivaren tydligt kommunicerar de valbara alternativen och vårdtagarens rättigheter. Öppenhet och tydlighet är en förutsättning för autonomi, valfrihet och informerat samtycke.

Möjligen ställer den genomgripande sensortekniken nya krav på informerat samtycke. En kontinuerlig dialog kan vara en rimlig åtgärd då vårdinsatsen eller vårdaren delvis blir osynlig när kontraktet väl har aktualiserats, till exempel i form av sensorbaserad omsorg. Vårdtagaren är visserligen medveten om att tillsyn kommer att ske med hjälp av sensorteknik när hon accepterar ett vårdprogram, men sensorbaserade tjänster kan integreras $\mathrm{i}$ hemmiljön och bli i det närmaste osynliga för användaren. Vårdtagaren kan övervakas utan att vara medveten om det när övervakningen sker och kan lätt glömma bort en dold övervakning.

\section{Sammanfattning}

Min översikt över framväxande IKT-baserat vård- och omsorgsstöd, vilket ibland kallas «skräddarsydd vård», är ingalunda uttömmande, och de etiska implikationerna förtjänar djupare analys. Den visar dock på att det är viktigt att redan på ett tidigt stadium diskutera under vilka villkor tekniken är önskvärd och etiskt försvarbar.

De primära målen bör vara att utveckla teknik som svarar mot reella behov och som stärker vårdkvaliteten. Det behövs empiriska studier av vårdtagares faktiska preferenser och prioriteringar för att säkerställa att teknikutvecklaren och vårdbeställaren utgår från vårdtagarens faktiska snarare än förmodade behov och preferenser. En vanlig föreställning är att äldre människor är negativa till ny teknik, eller åtminstone inte motiverade att sätta sig in i hur den fungerar. Det kan vara sant om vissa men inte med nödvändighet om alla äldre. Likaså antas ofta att gamla människor vill undvika risker och behöver riskförebyggande åtgärder. ${ }^{18}$ Sannolikheten att äldre drabbas av benbrott till följd av fall är generellt större än att unga människor gör det, men att skapa system och miljöer för att till varje pris undvika att gamla personer exponeras för risker kan leda till onaturligt säkra och sterila boendemiljöer. Sensorer och robotar i vårdtagarens hem kan programmeras för att varna vårdtagaren för att utföra vissa riskabla handlingar eller slå larm om hon utsätter sig för risk. Robotar kan även programmeras att utföra vissa praktiska sysslor, vilket kan vara ett välkommet stöd men också passivisera vårdtagaren. För att undvika oberättigad paternalism och passivisering bör införandet av vårdstödet föregås av diskussioner mellan vårdgivare och vårdtagare och andra berörda parter om trygghet och 
säkerhet liksom vad tekniken ska varna för och bistå med. I möjligaste mån bör man avhålla sig från att behandla äldre eller för den delen handikappade eller sjuka som en homogen grupp och tillskriva individer ur denna grupp behov, attityder och preferenser. För att undvika stereotypiseringar är det viktigt att på ett tidigt stadium involvera användarna i utvecklingen och införandet av vårdstöd, och om vårdstödet ska ge skäl för epitet som «skräddarsydd» eller «individanpassad» måste det utvecklas för patientens bästa, anpassas till hennes förutsättningar och preferenser och införas i samråd med henne (och inte sammanblandas med vårdgivarens önskan om att förbättra arbetssituationen för vård- och omsorgspersonal).

IKT-baserat vård- och omsorgsstöd kan underlätta för patienter som behöver kontinuerlig tillsyn men inte akut vård. Tekniken kan främja självständighet och trygghet och göra att äldre och handikappade som med visst stöd kan klara sig själva kan bo kvar i sin egen bostad. IKT-baserad vårdtillsyn möjliggör inte bara tätare virtuella vårdkontakter utan i vissa fall tillsyn över huvud taget. Även patienter i glesbygden där det annars vore svårt eller till och med praktiskt omöjligt kan få tillsyn. Vidare kan tekniken användas för att utbilda friska människor i ett preventivt syfte, för att de ska behålla hälsan.

Det framhålls ofta att IKT-stöd kan anpassas till individers unika behov, vilket främjar värden som är viktiga för vård och omsorg, som valfrihet, oberoende och autonomi (HNV 2009-2011). Samtidigt betonas att vårdrelationen bör kännetecknas av närhet, empati (Holm 1987), tillit och förtroende (Martinsen 1991). Alltför starka satsningar på tekniklösningar för att främja självständighet och kvarboende kan leda till en ökad isolering bland vårdtagare och det är ännu oklart i vilken utsträckning till exempel närhet kan förmedlas via videokommunikation. Olika typer av sensorteknik utvecklas för självhälsokontroll (preventiv såväl som reaktiv), vilket sägs främja en aktiv vårdtagare snarare än en passiv mottagare av vård. Men innebär dessa möjligheter ökat välbefinnande eller skapar de ökad oro? Lagring och hantering av personanknutna hälsodata ställer inte bara krav på informationssäkerhet och sekretess. Personspecifik och hälsorelaterad information som lagras i digitala arkiv och i implantat under huden kan komma att påverka vår självuppfattning och identitet, vilket förtjänar att uppmärksammas. Vidare kan implantat komma att påverka individers fysiska och mentala karaktär och förmågor på ett bestående sätt, och frågan om i vilken utsträckning den typen av teknik bör syfta till att reparera respektive förbättra individer aktualiseras.

Tekniken kan innebära kränkningar av vissa aspekter av den personliga integriteten och samtidigt främja andra. När man inför IKT-baserat vårdstöd bör målet vara att välja det minst integritetskränkande alternativet och att minimera de integritetskränkande aspekterna av den valda tekniken. Ett exempel kan vara att använda icke-identifierande sensorteknik i 
stället för identifierande kameror och att undvika att lagra insamlad information om det inte är nödvändigt. Eftersom den personliga integriteten är kontextberoende krävs en lyhördhet för hur olika vårdtagare förstår och prioriterar den personliga integriteten utifrån sina specifika situationer och behov. Studier indikerar att personer som behöver vårdstöd prioriterar säkerhet över integritet och välkomnar övervakningskapabel teknik (Essén 2008). Men utöver den upplevda tryggheten, innebär IKT-baserat vårdstöd också en ökad faktisk säkerhet?

En rad viktiga frågor som kräver fördjupad reflektion har väckts. Mest avgörande är vad som kännetecknar god vård och i vilken utsträckning och på vilka villkor tekniken bör tillåtas att ersätta vårdformer som innebär fysiska möten mellan vårdpersonal och vårdtagare. Vilka risker finns det med att ersätta den traditionella, manuella vården med IKT-baserat vårdstöd? Vilken, om någon, är den etiskt relevanta skillnaden mellan virtuell, artificiell vård och «reell» dito? Beroende på hur vi bedömer vikten av reell/virtuell/artificiell vård, kan vi behöva ompröva synen på rådande praxis.

För att identifiera en etiskt hållbar teknikanvändning inom vård och omsorg föreslås att teknikutveckling och implementering föregås av interaktiv etisk teknikvärdering där samtliga berörda parter făr komma till tals.

\section{Noter}

1 www.un.org/esa/population/publications/WPA2007/wpp2007.htm

2 Det vanligt förekommande antagandet att en åldrad befolkning kommer att innebära högre vårdkostnader förtjänar att problematiseras men kommer inte att diskuteras här.

3 http://www.epha.org/IMG/pdf/e-health_action_plan.pdf

4 Det är på sin plats att uppmärksamma läsaren på en medveten förenkling. Diskussionen fokuserar primärt på relationen vårdpersonal - vårdtagare, vilket är en grav förenkling av vård- och omsorgssituationen och i synnerhet när vårdtekniken flyttar hem till vårdtagaren. Berörda parter är inte bara vårdpersonalen (vilket bl.a inkluderar läkare, distriktssköterska och hemtjänst) och patienten utan även anhörigvårdare och andra anhöriga.

5 Några svenska termer motsvarande ambient, ubiquitous eller pervasive computing har inte fått fäste. I korthet är det en fråga om olika namn för samma tema inom olika forsknings- och utvecklingsområden. Engelskans ubiquitous betyder överallt närvarande och kommer från latinets ubique. Pervasive computing, som betyder genomträngande datateknik, är en annan term för mer eller mindre samma sak, vilken ofta används i amerikanska datatekniska sammanhang. Onödiga anglifieringar är vanligt förekommande inom området och behovet av begreppsreda påfallande. Till exempel används på svenska monitorering för engelskans monitoring. En risk är att det inte utvecklas någon terminologi på svenska, varför jag försöker introducera svenska termer som t.ex. genomgripande teknik eller integrerade informationssystem för de tre 
termerna ovan och uppföljning och kontroll i stället för monitorering. De här föreslagna termerna kan dock behöva preciseras.

$6 \mathrm{http} / / / \mathrm{vll}$. se/default.aspx?id=30 719\&refid=25 638

7 http://www.svd.se/nyheter/inrikes/aldre-ska-overvakas-med-kamera_4 $474655 . s v d$

8 http://www.myjoice.com/files/se/myjoice_produktblad_professionals.pdf

9 Se: www.cs.cmu.edu/ nursebotv

10 Se: http://www.sweden.se/eng/Home/Business/Innovation/Reading/Sweden-invests-in-robots-for-better-care/

11 Se: http://videosift.com/video/Tokyo-University-of-Science-Demos-a-new-Muscle-Suit

12 Se: http://www.sweden.se/eng/Home/Business/Innovation/Reading/Sweden-invests-in-robots-for-better-care/

13 Se: http://robotdalen.se/Projekt/Utvecklingsprojekt-Giraff-AB-i-Sverige/

14 http://www.aist.go.jp/aist_e/latest_research/2004/20 041 208_2/20 041 208_2.html

15 Detta kan möjligen bero på att relationen läkarepatient är skyddad i lag men även på att läkare har ett berättigat intresse att ta del av den här typen av information, vilket inte gäller för relationen patientpatient.

16 http://www.quantifiedself.com/ och http://www.curetogether.com/

17 Samtyckesprincipen garanterar en moraliskt försvarbar form för avtal/kontrakt mellan vårdgivare och vårdtagare men ställer inte några explicita krav på innehållet $\mathrm{i}$ avtalet. En fråga som återstår att besvara är; vad bör individer få samtycka till? Vårdgivaren är förvisso skyldig att verka i patientens intresse och aldrig agera till skada för denne.

18 www.atdementia.org.uk/content_files/files/

Accessing_Assisted_Living_Technology_protocol.pdf

\section{Litteratur}

Adams, A., Murata, K. \& Orito, Y. (2009) The Japanese sense of information privacy. AI \& Society, 24, s. 327-341.

Anderson, S. (2008) Privacy without the right to privacy. The Monist, 91 (1), s. 81108.

Beauchamp, T.L. \& Childress J.F. (2001) Principles of biomedical ethics, 5. utg. Oxford: Oxford University Press.

Banks, M.R. \& Banks, W.A. (2002) The effects of animal-assisted therapy and loneliness in an elderly population in long-term care facilities. Journal of Gerontology Series: Biological Sciences and Medical Sciences, 57(A), s. 428-432.

Bloustein, E.J. (1964) Privacy as an aspect of human dignity: An answer to Dean Prosser. New York University Law Review, 39, s. 6.

Coeckelbergh, M. (2010) Health care, capabilities, and AI assistive technologies. Ethical Theory and Moral Practice, 13 (2), s. 181-190.

Collste, G. (kommande) 'Under my skin'. The ethics of ambient computing for personal health monitoring. I The handbook of emergent technologies in social research, red. S. Biber-Hesse, s. 89-110. Oxford: Oxford University Press.

Dahlberg, K., Segesten, K., Nyström, M., Suserud, B-O. \& Fagerberg, I. (2003) Att förstå vårdvetenskap. Lund: Studentlitteratur. 
Datainspektionen. (2007) Ubiquitous computing - en vision som kan bli verklighet. Rapport. Wennersten, april 2007. Hämtad 13. oktober 2010 från http:// www.datainspektionen.se/Documents/rapport-ubiq-computing.pdf

Elster, J. (1983) Studies in the subversion of rationality. Cambridge: Cambridge University Press.

Essén, A. (2008) The two facets of electronic care surveillance: An exploration of the views of older people who live with monitoring devices. Social Sciences \& Medicine, 67 (1), s. 128-136.

Fischer-Huebner, S., Duquenoy, P., Zuccato, A. \& Martucci, L. (red.) (2008) Proceedings of the IFIP/FIDIS Summer School on "The Future of Identity in the Information Society", Karlstad, Sweden, 4-8 Augusti 2007. New York: Springer.

Gasson, M. (2008) ICT-implants. The invasive future of identity? IFIP International Federation for Information Processing, 262, s. 287-295.

Hildt, E. (2006) Electrodes in the brain: Some anthropological and ethical aspects of deep brain stimulation, Ethics of Information Technology in Medicine and Health Care, 5 International Review of Information Ethics (september), s. 3339.

Holm, U. (1987) Att förstå andra människors känslor. Stockholm: Natur och Kultur.

Hälsans nya verktyg (HNV). (2009-2011) Projektplan VINNOVA projekt. Hämtad 13. oktober 2010 från http://www.halsansnyaverktyg.se/

Inness, J. (1994) Privacy, intimacy and isolation. Oxford: Oxford University Press.

Jul, L. (2008) Adding values - smart textile options for Automotive Applications, The Nordic Textile Journal, 1. Hämtad 13. oktober 2010 från http://www.smarttextiles.se/filer/CTF_JOURNAL_0108.pdf

Kosta, E. \& Gasson, M. (2008) Deliverable D12.6: A Study on ICT-implants. The FIDIS consortium - EC Contract No 507 512. Hämtad 101013 från http:// www.fidis.net/fileadmin/fidis/deliverables/fidis-wp12del12.6.A_Study_on_ICT_Implants.pdf

Kosta, E., Pitkänen, O., Niemelä, M. \& Kaasinen, E. (2009) Mobile-centric ambient intelligence in health- and homecare-anticipating ethical and legal challenges. Science and Engineering Ethics, 6 (2), s. 303-323.

Lever, A. (2005) Feminism, democracy and the right to privacy, Minerva: An Internet Journal of Philosophy, 9, s. 131.

Mahoney, D.F., Purtiloa, R. F., Webbeb, F.M., Alwanc, M., Bharuchad, A.J., Adlame, T.D., Jimisonf, H.B., Turnerc, B. \& Beckerb, A. (2007) In-home monitoring of persons with dementia: Ethical guidelines for technology research and development. Alzheimer's \& Dementia, 3, s. 217-226.

Marini, B. (1999) Institutionalised older adults' perceptions of nurse caring behaviours. Journal of Gerontological Nursing, 25 (5), s. 11-16.

Martin, R., Williams, C. \& O’Neill, D. (2009) Retrospective analysis of attitudes to ageing in the Economist: Apocalyptic demography for opinion formers. British Medical Journal, 339 (b4914).

Martinsen, K. (1991) Omsorg, sykepleie og medisin, 2. utg. Otta: Engers Boktrykkeri.

Mattiasson, A.C. \& Hemberg, M. (1998) Intimacy - meeting needs and respecting privacy in the care of elderly people: What is a good moral attitude on the part of the nurse/carer? Nursing Ethics, 5 (6), s. 527-534.

Nissenbaum, H. (2004) Privacy as contextual integrity. Washington Law Review, 79 (1), pp. 119-158. 
O’Neill, D.J. (2003) Electronic tagging of people with dementia: Tagging should be reserved for babies, convicted criminals, and animals. British Medical Journal, 326, pp. 281.

Otto, C.A., Jovanov, E. \& Milenkovic, A. (2005) A WBAN-based system for health monitoring at home. Hämtad 13. oktober 2010 från http://www.ece.uah.edu/ $\sim$ milenka/docs/coejam_isss-mdbs06.pdf

Palm, E. (2005) The dimensions of privacy. I The ethics of workplace privacy, red. S.O. Hansson \& E. Palm, s. 157-174. Brussels: P.I.E. - Peter Lang.

Peter, F. (2004) Choice, consent and the legitimacy of market transactions. Economics and Philosophy, 20, s. 1-18.

Van der Ploeg, I. (2005) Biometric identification technologies: Ethical implications of the informatization of the body. BITE Policy Paper, 1. Hämtat 101013 från http://www.biteproject.org/documents/policy_paper_1_july_version.pdf

Regan, P.M. (1995) Legislating privacy. Technology, social values and public policy. Chapel Hill, NC: University of North Carolina Press.

Reuzel, R. (2004) Interactive technology assessment of paediatric cochlear implantation. Poiesis \& praxis: International Journal of Technology Assessment and Ethics of Science, 2 (2-3), s. 119-137.

Rodota, S. \& Capurro, R. (red.) (2005) Ethical aspects of ICT implants in the human body. Brussels: The European Group on Ethics in Science and New Technologies.

Rössler, B. (2005) The value of privacy. Cambridge: Polity Press.

Sandel, M. (2007) The case against perfectionism; Ethics in the age of genetic engineering. Cambridge, MA, London, UK: Harvard University Press.

Scanlon, T. (1975) Thomson on privacy. Philosophy and Public Affairs, 4, pp. 315322.

Sharkey, A. \& Sharkey, N. (2010) Granny and the robots: Ethical issues in robot care for the elderly. Ethics of Information Technology. DOI 10.1007/s10 676010-9234-6

Sidenwall, B., Fjellström, C. \& Ek, A. (1994) The meal situation in geriatric care intentions and experiences. Journal of Advanced Nursing, 20, s. 613-621.

Socialstyrelsens årliga lägesrapport (2010) Västerås: Edita Västra Aros. Hämtad 21. mars 2010 från http://www.socialstyrelsen.se/publikationer2010/2010-3-14/ Documents/2010-3-21\%20Lägesrapport\%202 010.pdf

Sparrow, R. \& Sparrow, L. (2006) In the hands of machines? The future of aged care. Minds and Machines, 16 (2), s. 141-161.

Sävenstedt, S. (2004) Telecare of frail elderly: Reflections and experiences among health personnel and family members. Doktorsavhandling, Umeå universitet.

Wass, M. (2009) Children with cochlear implants. Doktorsavhandling, Linköpings universitet.

Welsh, S., Hassiotis, A., O’Mahoney, G. \& Deahl, M. (2003) Big brother is watching you: The ethical implications of electronic surveillance measures in the elderly with dementia and in adults with learning difficulties. Aging and Mental Health, 7 (5), pp. 372-375.

Woogara, J. (2005) Patients' privacy of the person and human rights. Nursing Ethics, 12 (3), s. 273-287. 